\title{
Telomere Length and Risk of Glioma
}

\author{
Farzana Walcott $^{a}$, Preetha Rajaraman ${ }^{b, c}$, Shahinaz M. Gadalla ${ }^{d}$, Peter D. Inskip ${ }^{c}$, Mark P. \\ Purdue $^{\mathrm{e}}$, Demetrius Albanes ${ }^{\dagger}$, Esther Orr ${ }^{\mathrm{g}}$, Immaculata De Vivo ${ }^{\mathrm{g}, \mathrm{h}}$, and Sharon A. Savage ${ }^{\mathrm{d},{ }^{*}}$ \\ a Cancer Prevention Fellowship Program, Division of Cancer Prevention, National Cancer \\ Institute, National Institutes of Health, Rockville, MD 20892 \\ b Center for Global Health, National Cancer Institute, National Institutes of Health, Rockville, MD \\ 20892 \\ ${ }^{c}$ Radiation Epidemiology Branch, Division of Cancer Epidemiology and Genetics, National \\ Cancer Institute, National Institutes of Health, Rockville, MD 20892 \\ d Clinical Genetics Branch, Division of Cancer Epidemiology and Genetics, National Cancer \\ Institute, National Institutes of Health, Rockville, MD 20892 \\ e Occupational and Environmental Epidemiology Branch, Division of Cancer Epidemiology and \\ Genetics, National Cancer Institute, National Institutes of Health, Rockville, MD 20892 \\ ${ }^{f}$ Nutritional Epidemiology Branch, Division of Cancer Epidemiology and Genetics, National \\ Cancer Institute, National Institutes of Health, Rockville, MD 20892 \\ 9 Channing Laboratory, Department of Medicine, Brigham and Women's Hospital/Harvard \\ Medical School, Boston, MA 02115 \\ h Department of Epidemiology, Harvard School of Public Health, Boston, MA 02115
}

\begin{abstract}
Background-Telomere length in blood or buccal cell DNA has been associated with risk of various cancers. Glioma can be a highly malignant brain tumor and has few known risk factors. Genetic variants in or near RTELI and TERT, key components of telomere biology, are associated with glioma risk. Therefore, we evaluated the association between relative telomere length (RTL) and glioma in a prospective study.
\end{abstract}

Materials and Methods-We performed a nested case-control study within the Prostate, Lung, Colorectal, and Ovarian (PLCO) Cancer Screening Trial. RTL was determined by quantitative PCR on blood or buccal cell DNA obtained at least two years prior to diagnosis from 101 individuals with glioma cases. Healthy controls $(\mathrm{n}=198)$ were matched to cases $(2: 1)$ on age, gender, smoking status, calendar year, and DNA source. Conditional logistic regression was used to investigate the association between RTL and glioma.

Results-As expected, RTL declined with increasing age in both cases and controls. There was no statistically significant association between RTL and glioma overall. An analysis stratified by

\footnotetext{
*Corresponding Author Sharon A. Savage, M.D., F.A.A.P. Senior Investigator Clinical Genetics Branch Division of Cancer Epidemiology and Genetics National Cancer Institute 6120 Executive Blvd. EPS 7018 Rockville, MD 20892 Tel: 301-496-5785 savagesh@mail.nih.gov.

Publisher's Disclaimer: This is a PDF file of an unedited manuscript that has been accepted for publication. As a service to our customers we are providing this early version of the manuscript. The manuscript will undergo copyediting, typesetting, and review of the resulting proof before it is published in its final citable form. Please note that during the production process errors may be discovered which could affect the content, and all legal disclaimers that apply to the journal pertain.

Conflicts of interest

The authors have no potential conflicts of interest.
} 
gender suggested that short RTL ( $1^{\text {st }}$ tertile) in males was associated with glioma (odds ratio, [OR] $=2.29,95 \%$ confidence interval $[\mathrm{CI}]$ 1.02-5.11); this association was not observed for females (OR=0.41, 95\% CI 0.14-1.17).

Conclusions-This prospective study did not identify significant associations between RTL and glioma risk, but there may be gender-specific differences. Larger, prospective studies are needed to evaluate these findings.

\section{Keywords}

Telomere length; glioma; epidemiology; cancer risk

\section{INTRODUCTION}

Telomere length in surrogate tissues (e.g., blood or buccal cells) has been associated with cancer risk in several studies[1,2]. Telomeres are specialized nucleoprotein structures at chromosome ends that are critical for chromosomal stability. They shorten with each cell division and when critically short length is attained, cellular senescence or apoptosis is triggered[3]. Cancer cells continue to divide in the presence of short telomeres by upregulating key pathways, such as telomerase (TERT) or alternative lengthening of telomeres (ALT)[3].

Gliomas account for approximately 69\% of malignant brain tumors in the United States [4]. The five-year survival rate for all subtypes of glioma in the U.S. from 2001-2008 was approximately $45 \%$. High grade gliomas, such as glioblastoma multiforme, have a much worse outcome with a five-year survival rate of approximately $2.9 \%$ [5]. Gliomas are more common in males than in females[4, 6]. Confirmed risk factors for glioma include moderateto-high doses of ionizing radiation, certain inherited cancer predisposition syndromes, and a family history of glioma[7].

Genome-wide association studies (GWAS) of glioma have identified common susceptibility variants at seven loci, including two telomere biology genes, TERT and RTEL1[7-10]. Further, a recent study found increasing numbers of risk alleles in TERT and RTEL1 genes were associated with increased risk of glioma in older patients, while increasing numbers of risk alleles in CCDC26 and PHLDB lgenes was associated with younger age of diagnosis of glioma [11]. The association between telomere length and SNPs in TERT or RTEL1 is not clear; some studies have found associations whereas others have not [12, 13].

There is a growing connection between changes in telomere biology in somatic glioma tissues, including TERT promoter mutations in 83\% of glioblastoma multiforme [14]. Telomere length heterogeneity appears to be present in brain tumors. Some brain tumors appear to up-regulate telomerase whereas others maintain telomere length through the alternative lengthening of telomere pathway (ALT) [15-20]. The ALT pathway may play a role in specific subsets of glioma with mutations in Alpha Thalassemia/Mental Retardation $\mathrm{X}$-linked (ATRX) and/or isocitrate dehydrogenase genes (IDH1) [18].

In order to better understand the connection between germline telomere biology and glioma, we conducted a nested case-control study within the Prostate, Lung, Colorectal, and Ovarian Cancer (PLCO) Screening Trial. 


\section{METHODS}

\subsection{Study Design}

Our case-control study was nested within the prospective PLCO Screening Trial [21]. All

study participants were of European ancestry, cancer-free at enrollment, aged between 55-75 years, enrolled between 1993 and 2001, and followed until at least 2010. For our study, cases were individuals who developed glioma as a first cancer between 1995-2010. Controls were cancer-free at time of case diagnosis. Cases and controls (two per case) were matched on: trial randomization arm (control arm or intervention arm), gender, age at baseline in 4 categories $(55-59,60-64,65-69,70+)$, calendar year of randomization, cigarette smoking status (never, current, former), and calendar year of blood draw. In addition, cases and controls were fully matched on DNA source except for 17 cases where matching was for only one control. In order to minimize the possibility of reverse causality association, only biological specimens that were collected two or more years prior to diagnosis/selection were considered.

\subsection{Laboratory Methods}

DNA was extracted by standard methods (phenol:chloroform or Qiagen kits) from blood, buffy coat, or buccal cells. The average relative telomere length (RTL) was determined using qPCR as described previously[22, 23]. RTL was calculated as the telomere repeat copy number/single-gene (36B4) copy number (T/S) exponentiated ratio. Laboratory technicians were blinded to the case-control status. All assays were performed in triplicate on $5 \mathrm{ng}$ of genomic DNA. Forty blinded, randomly selected, quality control samples were interspersed throughout the dataset in order to assess inter-plate and intra-plate variability. The coefficient of variation (CV) for triplicate of the telomere copy (inter-assay) was $0.9 \%$ and for the single-copy gene was $0.8 \%$. The $\mathrm{CV}$ for duplicate quality control samples (intraassay) was $3.92 \%$ with a range of $0.42 \%-7.82 \%$.

\subsection{Statistical Analysis}

Spearman's rank correlation was used to assess correlations between RTL and age for cases and controls. We used Wilcoxon-rank test to compare median RTL in cases and controls overall, and by subgroup. Conditional logistic regression was used to examine the association between age-adjusted RTL and glioma. Stratified analyses by gender were performed to assess the interaction of gender and RTL on glioma risk. In all analyses, RTL was assessed as a continuous variable and in tertiles (based on the distribution in the controls). The final analysis included 198 controls and 101 cases (RTL data were not available on 12 controls and 4 cases due to qPCR assay failures). All analyses were performed using SPSS version 19. All tests were two-sided.

\section{RESULTS}

Per study design, the glioma cases and controls were similar in regard to age distribution, gender, and smoking status (Table 1). There were more males than females with glioma (male:female ratio 3:2). RTL was inversely correlated with age in the controls $(r=-0.14, \mathrm{p}$ $=0.04)$. The RTL-age correlation in the cases was not statistically significant $(r=0.10, \mathrm{p}=$ 0.34 ). The median RTL in glioma cases and controls was not significantly different (median RTL in cases $=0.74$ and in controls $=0.77, \mathrm{p}=0.84$ ). In the regression model, the evaluation of risk of glioma and RTL as both a continuous variable and in tertiles of RTL in controls revealed no statistically significant associations between RTL and overall risk of glioma (Table 2). Since RTL varies between tissues but is highly correlated within individuals we evaluated whether DNA sources affected our results [24-26]. Sensitivity 
analyses adding DNA source to the conditional logistic regression model made no difference (data not shown).

Case-case comparison of RTL showed that males with glioma had shorter telomeres than females with glioma (male cases median RTL $=0.63$, female cases median $\mathrm{RTL}=0.91, \mathrm{p}=$ 0.02) (Table 1). This relationship between RTL and gender was not observed in controls. However, gender-specific analyses suggested an association between RTL and glioma in males (continuous RTL p $=0.05$ and shortest RTL tertile/longest $\mathrm{OR}=2.29,95 \% \mathrm{CI}$ $1.02-5.11)$.

\section{Discussion}

The etiology of glioma is not well understood, although genetic factors, high levels of exposure to ionizing radiation, and male gender appear to be risk factors[7]. We conducted a case-control study of RTL in glioma because there is a growing body of evidence suggesting that aberrant telomere biology may be associated with glioma. Common germline variants in key telomere biology genes, RTELI and TERT, are associated with glioma risk [7-10]. Several studies have found a connection between telomerase levels, telomere heterogeneity, TERT promoter mutations and ALT in somatic glioma tissues and provide further evidence for a biological connection [14] [15-20]. A growing number of studies suggest that short germline RTL is a risk factor for certain cancers, including bladder, esophageal, gastric, head and neck, ovarian, renal and overall incident cancer[1]. However, many of these studies were limited by sample size and by their retrospective case-control nature. Recent prospective studies suggest that germline RTL may not be strongly associated with cancer risk but, instead, may be associated with early mortality [27, 28].

Evaluations of "brain and nervous tissue cancer" and RTL were included, to a limited degree, in a large prospective study of leukocyte RTL in 3,142 individuals with cancer from a cohort of 47,102 participants in two Danish cohorts [27]. That study included 65 individuals with brain and nervous tissue cancer. There were no statistically significant associations between RTL and risk of brain and nervous tissue cancer. However, the risk of early death after brain and nervous tissue cancer was increased in individuals with shorter telomeres (hazard ratio 1.52 , 95\% CI 1.00-2.31) [27].

Our study is the first to specifically evaluate RTL in prospectively collected buccal or leukocyte samples from glioma cases and controls. We did not find an association between overall glioma risk and germline RTL. However, our data suggest that males with short telomeres may be at increased risk of glioma compared with age-matched, cancer-free males. A larger sample size is required before drawing any firm conclusions.

A limitation of our study is that we were underpowered to stratify by tumor subtype. While subtypes of glioma may have different mechanisms of telomere maintenance, it is unclear if that would be reflected in a germline RTL study. Given the nature of glioma case and control sample availability in PLCO, our study is also limited because it included RTL measurements on blood and buccal cell DNA. We used sample source as a matching factor in the study design and performed sensitivity analyses that showed there was no difference in results based on sample source.

The strengths of our study include the well-characterized PLCO cohort, and its prospective nature with biologic samples collected at least two years prior to glioma diagnosis. In summary, our study suggests that germline RTL is not associated with overall glioma risk, but RTL may be associated with glioma in males. Larger studies of telomere biology and specific glioma subtypes are warranted to better understand its etiology and risk factors. 


\section{Acknowledgments}

We are grateful to the PLCO study participants for their valuable contributions. The PLCO Screening Trial was supported by individual contracts from the NCI to the University of Colorado Denver NO1-CN-25514, Georgetown University NO1-CN-25522, Pacific Health Research Institute NO1-CN-25515, Henry Ford Health System NO1CN-25512, University of Minnesota, NO1-CN-25513, Washington University NO1-CN-25516, University of Pittsburgh NO1-CN-25511, University of Utah NO1-CN-25524, Marshfield Clinic Research Foundation NO1CN-25518, University of Alabama at Birmingham NO1-CN-75022, Westat, Inc. NO1-CN-25476, University of California, Los Angeles NO1-CN-25404.

Financial support

This study was supported by the intramural research program of the Division of Cancer Epidemiology and Genetics, National Cancer Institute, National Institutes of Health.

\section{Abbreviations}

RTL relative telomere length

PLCO Prostate, Lung, Colorectal, and Ovarian Cancer Screening Trial

OR odds ratio

CI $\quad 95 \%$ confidence interval

qPCR quantitative PCR

\section{References}

1. Wentzensen IM, Mirabello L, Pfeiffer RM, Savage SA. The association of telomere length and cancer: a meta-analysis. Cancer Epidemiol Biomarkers Prev. 2011; 20(6):1238-50. [PubMed: 21467229]

2. Ma H, Zhou Z, Wei S, Liu Z, Pooley KA, Dunning AM, et al. Shortened telomere length is associated with increased risk of cancer: a meta-analysis. PLoS One. 2011; 6(6):e20466. [PubMed: 21695195]

3. Shay JW, Wright WE. Role of telomeres and telomerase in cancer. Semin Cancer Biol. 2011; 21(6): 349-53. [PubMed: 22015685]

4. Dolecek TA, Propp JM, Stroup NE, Kruchko C. CBTRUS statistical report: primary brain and central nervous system tumors diagnosed in the United States in 2005-2009. Neuro Oncol. 2012; 14(Suppl 5):v1-49. [PubMed: 23095881]

5. Ries, LAG. Cancer survival among adults : U.S. SEER program, 1988-2001, patient and tumor characteristics. U.S. Department of Health and Human Services, National Institutes of Health, National Cancer Institute; Bethesda, MD: 2007. SEER survival monograph.; p. 276

6. Dubrow R, Darefsky AS. Demographic variation in incidence of adult glioma by subtype, United States, 1992-2007. BMC Cancer. 2011; 11:325. [PubMed: 21801393]

7. Bondy ML, Scheurer ME, Malmer B, Barnholtz-Sloan JS, Davis FG, Il'yasova D, et al. Brain tumor epidemiology: consensus from the Brain Tumor Epidemiology Consortium. Cancer. 2008; $113(7$ Suppl):1953-68. [PubMed: 18798534]

8. Rajaraman P, Melin BS, Wang Z, McKean-Cowdin R, Michaud DS, Wang SS, et al. Genome-wide association study of glioma and meta-analysis. Hum Genet. 2012; 131(12):1877-88. [PubMed: 22886559]

9. Wrensch M, Jenkins RB, Chang JS, Yeh RF, Xiao Y, Decker PA, et al. Variants in the CDKN2B and RTEL1 regions are associated with high-grade glioma susceptibility. Nat Genet. 2009; 41(8): 905-8. [PubMed: 19578366]

10. Walsh KM, Rice T, Decker PA, Kosel ML, Kollmeyer T, Hansen HM, et al. Genetic variants in telomerase-related genes are associated with an older age at diagnosis in glioma patients: evidence for distinct pathways of gliomagenesis. Neuro Oncol. 2013; 15(8):1041-7. [PubMed: 23733245] 
11. Walsh KM, Rice T, Decker PA, Kosel ML, Kollmeyer T, Hansen HM, et al. Genetic variants in telomerase-related genes are associated with an older age at diagnosis in glioma patients: evidence for distinct pathways of gliomagenesis. Neuro Oncol. 2013

12. Mirabello L, Yu K, Kraft P, De Vivo I, Hunter DJ, Prescott J, et al. The association of telomere length and genetic variation in telomere biology genes. Hum Mutat. 2010; 31(9):1050-8. [PubMed: 20597107]

13. Bojesen SE, Pooley KA, Johnatty SE, Beesley J, Michailidou K, Tyrer JP, et al. Multiple independent variants at the TERT locus are associated with telomere length and risks of breast and ovarian cancer. Nat Genet. 2013; 45(4):371-84. 384e1-2. [PubMed: 23535731]

14. Killela PJ, Reitman ZJ, Jiao Y, Bettegowda C, Agrawal N, Diaz LA, et al. TERT promoter mutations occur frequently in gliomas and a subset of tumors derived from cells with low rates of self-renewal. Proceedings of the National Academy of Sciences. 2013

15. Kheirollahi M, Mehrazin M, Kamalian N, Mehdipour P. Alterations of telomere length in human brain tumors. Med Oncol. 2011; 28(3):864-70. [PubMed: 20373057]

16. Maes L, Van Neste L, Van Damme K, Kalala JP, De Ridder L, Bekaert S, et al. Relation between telomerase activity, hTERT and telomere length for intracranial tumours. Oncol Rep. 2007; 18(6): 1571-6. [PubMed: 17982646]

17. McDonald KL, McDonnell J, Muntoni A, Henson JD, Hegi ME, von Deimling A, et al. Presence of alternative lengthening of telomeres mechanism in patients with glioblastoma identifies a less aggressive tumor type with longer survival. J Neuropathol Exp Neurol. 2010; 69(7):729-36. [PubMed: 20535033]

18. Jiao Y, Killela PJ, Reitman ZJ, Rasheed AB, Heaphy CM, de Wilde RF, et al. Frequent ATRX, CIC, FUBP1 and IDH1 mutations refine the classification of malignant gliomas. Oncotarget. 2012; 3(7):709-22. [PubMed: 22869205]

19. Ferrandon S, Saultier P, Carras J, Battiston-Montagne P, Alphonse G, Beuve M, et al. Telomere profiling: toward glioblastoma personalized medicine. Mol Neurobiol. 2013; 47(1):64-76. [PubMed: 23065374]

20. Nguyen DN, Heaphy CM, de Wilde RF, Orr BA, Odia Y, Eberhart CG, et al. Molecular and morphologic correlates of the alternative lengthening of telomeres phenotype in high-grade astrocytomas. Brain Pathol. 2013; 23(3):237-43. [PubMed: 22928601]

21. Prorok PC, Andriole GL, Bresalier RS, Buys SS, Chia D, Crawford ED, et al. Design of the Prostate, Lung, Colorectal and Ovarian (PLCO) Cancer Screening Trial. Control Clin Trials. 2000; 21(6 Suppl):273S-309S. [PubMed: 11189684]

22. McGrath M, Wong JY, Michaud D, Hunter DJ, De Vivo I. Telomere length, cigarette smoking, and bladder cancer risk in men and women. Cancer Epidemiol Biomarkers Prev. 2007; 16(4):8159. [PubMed: 17416776]

23. Cawthon RM. Telomere measurement by quantitative PCR. Nucleic Acids Res. 2002; 30(10):e47. [PubMed: 12000852]

24. Daniali L, Benetos A, Susser E, Kark JD, Labat C, Kimura M, et al. Telomeres shorten at equivalent rates in somatic tissues of adults. Nat Commun. 2013; 4:1597. [PubMed: 23511462]

25. Gadalla SM, Cawthon R, Giri N, Alter BP, Savage SA. Telomere length in blood, buccal cells, and fibroblasts from patients with inherited bone marrow failure syndromes. Aging (Albany NY). 2010; 2(11):867-74. [PubMed: 21113082]

26. Friedrich U, Griese E, Schwab M, Fritz P, Thon K, Klotz U. Telomere length in different tissues of elderly patients. Mech Ageing Dev. 2000; 119(3):89-99. [PubMed: 11080530]

27. Weischer M, Nordestgaard BG, Cawthon RM, Freiberg JJ, Tybjaerg-Hansen A, Bojesen SE. Short Telomere Length, Cancer Survival, and Cancer Risk in 47102 Individuals. J Natl Cancer Inst. 2013

28. Willeit P, Willeit J, Mayr A, Weger S, Oberhollenzer F, Brandstatter A, et al. Telomere length and risk of incident cancer and cancer mortality. JAMA. 2010; 304(1):69-75. [PubMed: 20606151] 
Table 1

Descriptive Characteristics and Median Telomere Length of Study Participants

\begin{tabular}{|c|c|c|c|}
\hline & Cases $\mathrm{N}=102(\%)$ & Controls N=199 (\%) & $P$ value \\
\hline \multicolumn{4}{|l|}{ Age } \\
\hline $55-59$ & $27(26)$ & $50(25)$ & \\
\hline $60-64$ & $31(31)$ & $61(31)$ & 0.90 \\
\hline $65-69$ & $31(31)$ & $60(30)$ & \\
\hline $70+$ & $13(13)$ & $28(14)$ & \\
\hline \multicolumn{4}{|l|}{ Gender } \\
\hline Males & $62(61)$ & $122(62)$ & 0.90 \\
\hline Females & $40(40)$ & $77(39)$ & \\
\hline \multicolumn{4}{|c|}{ Smoking status } \\
\hline Never & $54(51)$ & $105(53)$ & \\
\hline Former & $6(6)$ & $11(6)$ & 0.99 \\
\hline \multirow[t]{2}{*}{ Current } & $42(42)$ & $83(42)$ & \\
\hline & Median Relative Telomere Length (Range) & Median Relative Telomere Length (Range) & \\
\hline All & $0.74(0.20-4.77)$ & $0.77 \S(0.14-3.72)$ & 0.84 \\
\hline Males & $0.63(0.22-2.15)$ & $0.77^{\S}(0.14-3.72)$ & 0.12 \\
\hline Females & $0.91 \S \S(0.20-4.77)$ & $0.77 \S(0.16-3.56)$ & 0.10 \\
\hline \multicolumn{3}{|c|}{ Male glioma cases vs. female glioma cases } & 0.02 \\
\hline
\end{tabular}


Table 2

Age-adjusted association between relative telomere length and glioma

\begin{tabular}{|c|c|c|c|c|c|}
\hline \multicolumn{6}{|c|}{ All participants } \\
\hline & Cases N (\%) & Controls N (\%) & $\mathbf{O R}{ }^{*}$ & CI $(95 \%)$ & $P$ value \\
\hline RTL (continuous) & 102 & 193 & 0.84 & $0.55-1.27$ & 0.84 \\
\hline RTL (median) & 102 & 192 & 1.17 & $0.73-1.88$ & $0.52^{\S}$ \\
\hline \multicolumn{6}{|l|}{ Tertiles of RTL } \\
\hline Short ( $1^{\text {st }}$ tertile $)$ & $36(36)$ & $65(33)$ & 1.26 & $0.69-2.29$ & 0.46 \\
\hline Medium ( $2^{\text {nd }}$ tertile $)$ & $32(32)$ & $67(34)$ & 1.06 & $0.55-2.04$ & 0.86 \\
\hline Long ( $3^{\text {rd }}$ tertile $)$ & $33(33)$ & $66(33)$ & 1.00 & \multicolumn{2}{|c|}{ REF } \\
\hline \multicolumn{6}{|c|}{ Males only } \\
\hline Continuous RTL & 62 & 116 & 0.48 & $0.23-0.99$ & 0.05 \\
\hline RTL (median) & 62 & 116 & 1.74 & $0.93-3.24$ & 0.081 \\
\hline \multicolumn{6}{|l|}{ Tertiles of RTL } \\
\hline Short ( $1^{\text {st }}$ tertile) & $29(46)$ & $38(31)$ & 2.29 & $1.02-5.11$ & 0.04 \\
\hline Medium ( $2^{\text {nd }}$ tertile $)$ & $18(30)$ & $47(38)$ & 1.17 & $0.47-2.87$ & 0.74 \\
\hline Long ( $3^{\text {rd }}$ tertile $)$ & $14(22)$ & $37(30)$ & 1.00 & \multicolumn{2}{|c|}{ REF } \\
\hline & & & \multicolumn{3}{|c|}{$\mathrm{P}$ trend $=0.06$} \\
\hline \multicolumn{6}{|c|}{ Females only } \\
\hline Continuous RTL & 40 & 77 & 1.25 & $0.74-2.12$ & 0.41 \\
\hline RTL (median) & 40 & 76 & 0.64 & $0.30-1.37$ & 0.25 \\
\hline \multicolumn{6}{|l|}{ Tertiles of RTL } \\
\hline Short ( $1^{\text {st }}$ tertile) & $7(17)$ & $27(35)$ & 0.41 & $0.14-1.17$ & 0.09 \\
\hline Medium ( $2^{\text {nd }}$ tertile) & $14(35)$ & $20(26)$ & 1.21 & $0.45-3.28$ & 0.70 \\
\hline Long ( $3^{\text {rd }}$ tertile $)$ & $19(47)$ & $29(38)$ & 1.00 & \multicolumn{2}{|c|}{ REF } \\
\hline & & & \multicolumn{3}{|c|}{$\mathrm{P}$ trend $=0.15$} \\
\hline
\end{tabular}

Abbreviations: RTL, relative telomere length; OR, odds ratio; $\mathrm{CI}, 95 \%$ confidence interval; $\mathrm{N}$, number; $\mathrm{REF}$, reference

* Conditional logistic regression with matching on age, gender, and smoking status

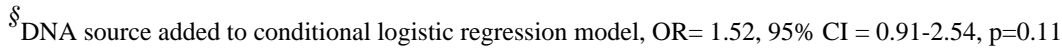

